\title{
Research on Miao Martial Arts Drum Dancing in Xiangxi
}

\author{
Zhenghong $\mathrm{Li}^{1, \mathrm{a}^{*}}$, Xunci Liu ${ }^{1, \mathrm{~b}}$ and Zhenhua Guo ${ }^{1, \mathrm{c}}$ \\ ${ }^{1}$ College of Sports Science, Jishou University Renmin South Road 120, Jishou City Hunan Province, \\ China

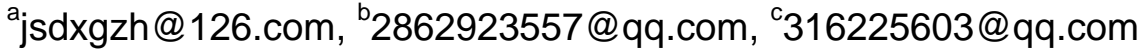

Keywords: Miao Martial Arts Drum Dancing; Origin; Development; Xiangxi

\begin{abstract}
Miao martial arts drum dancing, combining sports with art, shows the two features wiht national characters and artistry. This paper, using the field investigation method, literature method and so on, the history origin, main forms, inheriting way, main characteristics and survival status of Miao martial arts drum dancing are studied. The results showed: Miao martial arts drum dancing has such values as fitness value, art and social culture value and so on. At the same time, modern diversified forms of entertainment have some impact on martial arts drum. The phenomenon embodies : Local people do not pay much attention to Miao martial arts drum dancing; Cultural heritage protection consciousness is not strong; Inheritance people are very old; Cultural quality is generally not high; The local economic level is relatively backward, which restricts the extensive development of martial arts drum, and so on.
\end{abstract}

\section{The Origin of Miao Martial Arts Drum Dancing}

Miao Likes Drum Dancing very much, which Created a Good Social Environment for the Birth of the Martial Arts Drum Dancing. Miao drum is the most common traditional sports event with the most national characteristics, which spreads in Jishou city, Fenghuang county, Luxi county, Baojing county, Huayuan county, Guzhang county and so on in Jishou Tujia and miao autonomous prefecture of Hunan province. Miao drum dancing has a long history, according to the historical literature, it originated from before Han dynasty, produced in the sacrificial rites of Miao.Miao drum has two kinds: Festival drum and god celebration drum. When spring festival, April 8th, drilling-bull sacrifice for ancestors worship come, Miao will have grand performance of drum dancing, ancestor worship and entertainment gods, invoke the protection of god. Because of the miao culture, history and aesthetic factors, Miao drum dancing, through the narrative style, forms the unique personality. It recreates the pictures of Miao people's life and work by a vivid dancingaction. So, it is a picture of Miao historical picture scroll and is a collection of traditional cultural symbols. There are dozens of types of dances in Miao, such as flower-drum dance, reunion drum dancing, monkey drum dancing, women's single drum dacning, man single drum dancing, etc. Its no wonder, then, that Miao martial arts drum dancing generated in such environment.

Martial National Character Inspired the Creative Inspiration. In Miao culture, a very significant feature is the developed martial arts worship, the intensity of the martial spirit, that is to say, the warrior is the distinguishing feature of Miao culture. Its tough, strong morals not only can be found in the history of the text, but also from Miao's vocal art culture, totem culture and all aspects of hero worship. The founder Hong Fuqiang of Miao martial arts drum dancing is a master of Miao martial arts.

Hong Fuqiang, was born in Mita village, Hulu town, Bojing countr, Hunan province on January 30, 1936. Miao rich folk culture influences his life all the time, he is good at Miao song, Miao dances, Miao martial arts, flower drum dancing, greet ing guests drum dancing, monkey drum dancing. However, Hong Fuqiang doesn't satisfied with such. When he teaches his disciples, he often join the new action into Miao drum dancing. He melts the living elements such as forging iron, Dragon Boating, towing a boat, catching fish and shrimp into Miao drum dancing. Through his efforts and constant innovation, Miao drum dancing shows a new vigor and vitality. Just because of this, more 
and more people visit him and learn new drums and skilsl from him. After his retirement in 2002, Hong Fuqiang specializes in teaching drum dancing at home.

In 2003, Hong Fuqiang had the inspiration to unwrapped Miao "Bahe boxing" forms one by one. He drew the sketch, deduced more than 50 drum dancing actions. He played, he changed, again and again. Then a set of new martial arts drum "Bahe Drum" generated. "Bahe Drum" is called earliest martial arts drum, and Hong Fuqiang is called the earliest founder of Miao's martial arts drum dancing.The emergence of the "Bahe Drum", changed the traditional way of playing the drums with single drum and single play. Gradually, it became tens of people playing tens of drums hundreds of people playing hundreds of drums, thousands of people playing thousands of drums. Especially, they are suitable for all kinds of opening and closing ceremonies. Under the inspiration and guidance of Hong Fuqiang, Miao in Lv Dongshan set off an upsurge of creating new drum. "Hanshan Drum", "Xiangquan Drum", "Bagua Drum" were born in succession. Martial arts drum has become a beautiful scenery line there. In February 2008, Hong Fuqiang was honored with state-level non-material cultural heritage project representative inheritance people title of Miao drum dancing because of this. Lv Dongshan area is called the cradleland of Miao martial arts drum.

\section{The Main Forms of Miao Martial Arts Drum}

The most outstanding characteristic about Miao drum is to simultaneously play the surface of the drum and play the edge of drum. The preside is the drumbeats the person hits the surface of drum, the accompaniment is the drumbeats the person hits the edge of the drum. The people dances while she hits the surface of the drum. One person hits the surface while the other hits the edge of drum. They cooperate with each other. Martial arts drum is so too. But martial arts drum and its group play is its innovative main expression. Which is that one person hits the edge while the other people hit the surface of the drum. At the present, there are "Bahe Drum", "Hanshan Drum", "Youyi Drum", "Xiangquan Drum", "Bagua Drum". "Hanshan Drum" is created by Long Zilin, who is a villager from Hulu Town at Lvdong mountain. What is the same with Bahe Drum is Hanshan drum blends the essence of Miao martial arts into drum dancing, which makes the Hanshan Drum stiffness, grand and spectacular. What Hanshan Drum shows is the war scene that Miao' s ancestors resisted foreign enemy, which is reflected by more than 10 movements such as sweeping away the millions of enemy troops, overturning rivers and seas and so on. On the 50th anniversary celebration of Xiangxi Tujia and Miao autonomous prefecture establishment, 600 people carrying 500 drums from Baojing County played Hanshan Drum, the drum dancing with its magnificent momentum conquered many audiences on the spot. So far, more and more people are learning Hanshan Drum. It is learned that the practitioners that are learning Hanshan Drum are as many as tens of thousands of people. The students that Long Zilin teaches are more than three thousand people. What is the same with Bahe Drum is Youyi Drum, Xiangquan Drum, Bagua Drum are all taking Youyi boxing, Xiang Boxing and Bagua boxing as their action elements, which not only reflects the relaxation, lively, beauty, but also embodies the Miao boxing' s stretch, strong and powerful. The pace of the players is flexible. The drumbeats are sometimes slow and sometimes soft, sometimes active, sometimes breathtaking, touching people's mind.

\section{Inheritance Ways of Miao Martial Artsdrum}

Teacher and Pupil Inheritance. Miao martial arts drum lays emphasizes the coordination of pace with action. A lot of martial arts movements emphasizes the higher coordination of body, which requires the players to be familiar with diversified technology. When teachers teaches someone learn Miao martial arts drum, they often adopts the teaching methods by one-on-one. This way of teacher and pupil inheritance is an important heritance way that can always keep high technology level. The skills of the talented players is also improved in this way. 
The Inheritance in a Specific Environment. The inheritance in a specific environmental refers to that all the people on the spot are all inspired in a certain festive mood or a party atmosphere to be encouraged to take part in the activity of drum dancing. The masses have a wonderful time from the drum dancing, and make the drum dancing be inherited and developed, which is important for the inheritance and the development.

Generally, Miao drum dancing appears in Miao folk festival and event. For example, "April 8th", before and after the Spring Festival every year, Celebrating harvest, drilling-bull sacrifice, catching the autumn, Wedding, meeting guests and so on. Miao drum dancing is developing constantly, whose inheritance and change can't go without the specific environment.

\section{The Value of Miao Martial Arts Drum Dancing}

The National Spirit Value. Miao drum is Miao's treasure. Since ancient times, Miao people's spirit and belief have been included in Miao's martial arts drum dacing. To protect the Chinese traditional art treasures Miao martial arts drum dancing will play an irreplaceable role in improving the Miao people's national sense of responsibility, strengthening the cultural quality, constructing harmonious society, cultivating Miao people's tenacious spirit, having the courage of creation.

The Cultural and Artistic value. In the history of the Miao, Miao drum dancing gave a birth in the worship of the Miao nationality, which often alternatively jointed the performance with Nuo song, Nuo opera. To deeply explore Miao martial arts dancing and rescue it will have an underestimated function for saving Chinese dance, Chinese music, Chinese Nuo culture and so on.

The Value of Tourism Development. Miao martial arts drum dancing has the style with simplicity, enthusiasm, wildness, so it becomes performance event in a lot of scenic spots, loved by tourists. Miao martial arts drum has became a Miao' s brand in Dehang Village at Jishou city and Shangjiang Village at Fenghuang County.

The Sports Valu. Miao martial arts drum dancing taking as Miao people's exercise program, its sports value is obvious, which is mainly about its fitness: Completing a set of martial arts drum dancing generally needs more than 3 minutes, some over 10 minutes. Playing Martial arts drum requires action stretch, to be vigorous and forcible, Continuously jump more than 150 times. From the perspective of the rhythm of movement, Miao martial arts drum dancing belongs to moderate intensity aerobic exercise, which can effectively promote the metabolism of the body breathing and blood system, promote the improvement of the function of all the body organs, at the same time, it has the very good effect on coordination and flexibility of the body.

\section{Inheritance Ways of Miao Martial Artsdrum the Main Problems that Miao Martial Arts Drum Facing}

The Players for Playing Drums Are Many, Researchers of Compose Music Are Few. During on-the-spot investigation, the author found that there are professional teams in Aizhai village of Jishou, Jishou people's square, Sanjiang of Fenghuang, Lv liangshang area and the surrounding villages, such as Dehang village, Zhaiyang village, Hangsha town, Hulu town and so on. And in the local, Many people can play the drums, which is very common. But due to the relative lack of cultural knowledge, most of the local Miao people tend to learn playing the drums by constantly seeing and hearing. Even if they learn skills from master teachers, they just a simple learning. They seldom go to research it, not to mention composing music and choreography.

Shows are More, Arrangement is Single. With the development of cultural tourism in western Hunan, more and more tourists and delegations come here. When the guests come, the local drum teams will greet guests by playing greeting drums. The local professional team of the drums are often invited to play Miao martial arts drums all over the country. The most common Miao drums for performance are "Monkey Drum", "Moving Mountains Drum", "Bahe drum". The prospects of Miao cultural tourism is good, and the tourists are increasing, Miao drum performance has had scale. If 
they blindly repeat the performances and lack the innovation, which is bound to affect the sustainable development of Miao tourism.

Text Data is Few and no Special Writing. The author has not collected the related specialized writings about Miao martial arts drum during the investigation. The elated text data is also very few. The data collected is the form of video disc. Through the investigation, the county folk affairs committee in the region have compiled<miao myth and songs>, which included the local Miao song, but rarely involved the drums. In terms of current text data collected at the present, even the study of Miao drum only refers to all kinds of academic books or journal articles, one of the most representative is Shi Qigui's <Miao on-the-spot investigation report $>$ and Yu Xiqian's $<$ Drum Culture in Southern China and regional community life>.During the visit, the author saw that even though the famous drum players don't have the consciousness of recording what they have learned by writing. Imparting is limited to oral and practical operation. Due to the teaching by Miao language, the inheritance and spread of Miao marital arts drum is restricted geographically.

\section{Conclusion}

Miao Martianl Arts Drum Dancing is one of Miao Drum Dancings, which is the Intangible Cultural Heritage Protection Project in China. At present, there are mainly <Bahe drum $>,<$ moving mountains drum $>,<$ Youyi drum $>,<$ Bagua drum $>$. Hong Fuqiang, because of his invention of Bahe drum, is called the ancestor of Miao martial arts drum dancing. Lv Dongshan is the cradleland of Miao martial arts drum dancing.

Miao Martial Arts Drum Dancing and its Group Play are its Main Expression of Innovation. The survival value of martial arts drum dancing is mainly manifested in the sports value, artistic value and social value.

The Main Problems Miao Martial Arts Drum Dancing Facing are that the Players for Playing Drums are many, Researchers of Compose Music are few, Shows are more, Arrangement is Single. Text data is few and no Special Writing; At the same time, the modern entertainment diversity has great impacts on Miao martial arts drum dancing; Do not have a high level of understanding about Miao martial arts drum dancing, have no cultural heritage protection consciousness; The ageing of Inheritors is in critical condition; Cultural quality is generally not high; The economic level is relatively backward. All these restricted the extensive development of Miao martial arts drum dancing.

Advices. 1) Departments should organize experts and relevant personnel to conduct in-depth research on martial arts drum dancing.

Do well written records and collect the related data, collect the audio and video data. These are all very good protection measures to rescue Miao martial arts drum dancing. Martial arts drum dancing of Xiangxi Miao Facing the loss can get continuing and inheritance.

2) Promotion strategy, make sure to pass it on continuously

People's aesthetic concept constantly changing with the Times changes. Therefore, Xiangxi martial arts drum also should change according to the situation. Change the development strategy. Change it at any time and. To make a study on the basis of inheriting tradition. Abandon bad cypress, take its essence and carry it on.

3)Investment strategy, laying solid foundation of development.

Government should, first of all, realize and recognize the value of martial arts drum dancing on people's life, spiritual value and business value. The government should lead by example, put forward some good development policy and protection measures, call on people to get to know, protect, inherit and develop martial arts drum dancing which has a huge role in promoting people's national pride and national sense of responsibility in the western Hunan province and also can pave the way to the development of martial arts drum dancing, which has a certain reference value and guiding significance for the development of martial arts drum dancing. 


\section{Acknowledgements}

The national social science fund(12BTY046);Social science fund project of hunan province (15 YBA318); Scientific research key project of Hunan province department of education (15A154); Open-end fund project of national sports key research base of State general sports administration (14jdzb023).

\section{References}

[1] The cultural office of hunan province. Hunan province non-material cultural heritage list 1[M], Changsha, Hunan People Publishing House, 2009:497.

[2] Yu Xinping, Dance culture and Aesthetics[M], Beijing, Renmin university of China publishing house, 2005:20.

[3] Wu Xinfu, The History of Miao Culture [M]. Sichuan minorities press, Chengdu, Sichuan National Publishing House, 2009:19.

[4] Pen Cunkuai, Morphological characteristics and music characteristics of Xiangxi Miao Drum Dancing[J], The Arts Sea, 2010:3.

[5] Chen Xuan, On protection of Xiangxi Miao Drum Dancing[J], Succession(Education),2010(9):260-261.

[6] Pen Cunkuai, The inheritance and Protection of Xiangxi Miao Drum Dancing, The Art Sea,2010(6):118-119.

[7] Chen Li, Survival Present Situation and the Development Countermeasure Research of Xiangxi Miao's Drum[D], China academy of art, 2014:17.

[8] Ding Jie, Wu Xiulin, Xiangxi Folk Treasures - Interpretation of the connotation and value of Xiangxi Miao Drum Dancing[J], Sichuan Drama, 2009:1.

[9] Luo Wanhong, Research on Historical Background and Classification of the Drum Dance of Miao Nationality in West Hunan[J], Journal of Huahua College, 2008:12.

[10] [10]Xiao Can, The art characteristics and contemporary development of Xiangxi Miao Drum Dancing[J], Journal of Yangtze University(Socail Sciences),2012:4. 